\begin{tabular}{|l|l|}
\hline Postprint Version & 1.0 \\
\hline Journal website & http://hpq.sagepub.com/content/16/2/274.long \\
\hline Pubmed link & http://www.ncbi.nlm.nih.gov/pubmed/20733011 \\
\hline DOI & $10.1177 / 1359105310372976$ \\
\hline
\end{tabular}

This is a NIVEL certified Post Print, more info at http://www.nivel.eu

\title{
The Development of and First Experiences with a Behavioural Self-regulation Intervention for Endstage Renal Disease Patients and Their Partners
}

\author{
DAPHNE L. JANSEN ${ }^{1}$, MONIQUE HEI JMANS ${ }^{1}, \&$ MIEKE RI JKEN ${ }^{1}$, AD A. KAPTEIN ${ }^{2}$
}

${ }^{1}$ NIVEL Netherlands Institute for Health Services Research, The Netherlands

${ }^{2}$ Leiden University Medical Centre, The Netherlands

\begin{abstract}
This article describes the development of an intervention programme for patients with end-stage renal disease (ESRD) and their partners. The programme is based on theories of self-regulation, social learning, and self-determination aimed at maintaining and increasing patients' activities, including paid work, and sense of autonomy. The intervention was evaluated on its feasibility and first experiences among a group of 12 patients and partners. Results show that the intervention is feasible. The outcomes observed by the patients themselves are encouraging. The findings show that an approach in which cognitive, emotional, behavioural, and contextual aspects are integrated is promising. Areas of attention for developing and implementing interventions are discussed.
\end{abstract}

\section{INTRODUCTION}

END-stage renal disease (ESRD) refers to the point at which a patient with renal failure can no longer survive on existing kidney function and must undergo renal replacement therapy. At the end of 2005, about 1.9 million people were receiving renal replacement therapy worldwide, with about threequarters treated by dialysis and one-quarter by kidney transplant (Grassman, Gioberge, Moeller, \& Brown, 2006). ESRD patients on dialysis experience multiple symptoms such as pain, fatigue, pruritus and constipation (Murtagh, Addington-Hall, \& Higginson, 2007). In addition, they experience impaired physical, mental, and social functioning compared to the general population (e.g. Khan et al., 1995;Merkus et al., 1997, 1999;Mittal, Ahern, Flaster, Maesaka, \& Fishbane, 2001). The combination of dialysis and employment seems particularly difficult. Dialysis patients aged 18-64 years work less compared to the general working age population (Braun Curtin, Oberly, Sacksteder, \& Friedman, 1996; Theorell, Konarski- Svensson, Ahlmen, \& Perski, 1991; Van Manen et al., 2001). It is notable that many renal patients resign from their jobs during the period in which they are being prepared for renal replacement therapy. In a Dutch study only 35 percent of the ESRD patients of working age were still employed at the start of dialysis, compared to 61 percent in the general population (Van Manen et al., 2001). A review of the literature shows that work is generally beneficial to people's physical and mental health and well-being, and unemployment is associated with negative health effects (Waddell \& Burton, 2006).A literature study by Heijmans and Rijken (2004) revealed two psychological factors that may be closely linked to employment in ESRD patients, in addition to disease and sociodemographic characteristics: the patient's perceptions of illness and treatment, and social support including over-protection. These psychological factors, which have not been studied systematically, are interesting as they could be altered (Moss-Morris, Humphrey, Johnson, \& Petrie, 2007; Petrie, Cameron, Ellis, Buick, \& Weinman, 2002). Therefore, we investigated how ESRD patients' cognitive representations of their illness and treatment and the type of support that they experience are associated with participation in employment, feelings of autonomy, and self-esteem. In 2006 questionnaires 
Jansen, D.L., Heijmans, M., Rijken, M., Kaptein, A.A. The development of and first experiences with a behavioural self-regulation intervention for end-stage renal disease patients and their partners. Journal of Health Psychology: 2011, 16(2), 274-283

were sent to 248 dialysis patients and 185 patients being prepared for dialysis. The response rate was 67 percent and 59 percent respectively. We found that perceptions of illness and treatment contributed significantly to the variance in perceived autonomy and self-esteem, after controlling for sociodemographic and clinical characteristics. Beliefs of personal control over the illness, less perceived impact of the illness and its treatment, and less concern about the illness were the most important predictors of perceived autonomy and self-esteem (Jansen et al., submitted; Jansen, Rijken, Heijmans, \& Boeschoten, in press). With respect to employment status, consistent bivariate relationships with perceptions of the illness and treatment were observed in both patient groups. However, these relationships did not reach statistical significance due to the low number of working age patients. Furthermore, the results showed that social support by significant others, and overprotection by significant others and doctors, made an important contribution to the explained variance in perceived autonomy and self-esteem in dialysis patients. In addition, unemployment was related to perceived over-protection by doctors (Jansen, Heijmans, Boeschoten, \& Rijken, 2009).

\section{DEVELOPMENT OF INTERVENTION}

We decided to develop a psychological intervention which targeted these factors in order to maintain or widen ESRD patients' daily activities, including paid work, and to increase patients' feelings of autonomy. The content of the intervention is based on the results of our empirical study and three theoretical models: self-regulation theory, by Leventhal and colleagues (Leventhal, Meyer, \& Nerenz, 1980; Leventhal, Nerenz, \& Steele, 1984); social learning theory, by Bandura (1977); and self-determination theory, by Deci and Ryan (1985).

\section{Self-regulation theory}

Illness perceptions are a key component of Leventhal's Common SenseModel of self-regulation of health and illness (Leventhal et al., 1980, 1984). According to this model, people make sense of a health threat by developing their own cognitive representation of that threat. These representations generally contain the following factors:

the name of the illness and the range of symptoms that the patient believes are associated with the condition;

beliefs about the cause of the illness and how long it will last;

beliefs about the personal consequences of the condition for the patient and their family; and the extent to which the illness is amenable to personal control or to control through treatment (Petrie, Jago, \& Devcich, 2007).

These representations determine how patients respond to their illness on a behavioural and emotional level. Besides representations of illness, patients' beliefs about treatment also play a role in how they cope with their illness (Horne, 1997, 2003). Research has shown that positive perceptions of illness and treatment are associated with various patient outcomes (Hagger \& Orbell, 2003; Petrie \& Weinman, 1997; Petrie et al., 2007). Studies among ESRD patients demonstrate that their illness representations and treatment beliefs are associated with health-related quality of life (Griva, Jayasena, Davenport, Harrison, \& Newman, 2009; Timmers et al., 2008). Petrie and colleagues (Petrie et al., 2002; Petrie, Weinman, Sharpe, \& Buckley, 1996) were one of the first to translate the principles of self-regulation theory into a hospital intervention in order to change perceptions of illness after myocardial infarction. The results of a randomized-controlled trial (RCT) study showed that the intervention produced improved functional outcome and an earlier return to work. Arecent pilot study demonstrated that a simple intervention to change haemodialysis patients' perceptions of phosphate- binding medication improved their beliefs and knowledge about their treatment immediately after the intervention, in comparison to a control group (Karamanidou, Weinman, \& Horne, 2008).

\section{Social learning theory}

According to Bandura's $(1977,1997)$ social learning theory, human beings learn by observing how other people behave. The use of peer modelling and peer support are approaches grounded in this theory. Central concepts within this theory are selfefficacy and expectations of outcome. Self-efficacy is a person's belief 
Jansen, D.L., Heijmans, M., Rijken, M., Kaptein, A.A. The development of and first experiences with a behavioural self-regulation intervention for end-stage renal disease patients and their partners. Journal of Health Psychology: 2011, 16(2), 274-283

in their own ability to perform a particular behaviour successfully, and outcome expectations are beliefs about the effectiveness of the behaviour. These cognitive processes play an important role in the acquisition and retention of new behaviour. Improving patients' belief in selfefficacy is a key element of the Chronic Disease Self-Management Programme (Lorig et al., 2001): results from a RCT study showed that at six months and two years after the start of the programme, the participants experienced an increase in selfefficacy, well-being, health behaviours, and physical health status in comparison to the control group (Lorig et al., 1999, 2001).

\section{Self-determination theory}

Self-determination theory emphasizes the importance of autonomy for an individual's well-being (Deci \& Ryan, 1985). One is autonomous to the degree that one experiences choice, willingness, and personal endorsement of one's actions.According to self-determination theory, the successful accomplishment of desired behaviours occurs when people themselves view this behaviour as important, and not because the behaviour is achieved through pressure or coercion by others. Contexts that support autonomy facilitate more autonomous regulatory processes, and thus promote an effective change in behaviour. Support for autonomy in various contexts has been associated with psychological well-being and improved health behaviours (Baard, Deci, \& Ryan, 2004; Deci, La Guardia, Moller, Scheiner, \& Ryan, 2006; Kasser \& Ryan, 1999; Williams et al., 2006; Williams, Rodin, Ryan, Grolnick, \& Deci, 1998). Patients' family members are probably the most important actors within the patients' social context: they play an important role in a patient's adjustment to the illness (Martire, 2005). Clark and Dunbar (2003) translated the principles of selfdetermination theory into a family partnership intervention, in which the family members of heart failure patients learned how to develop behaviours that support autonomy, and the patients learned how to achieve the support they felt was needed in an effective and positive way. The results of an experimental pilot study demonstrated that patients who received this family partnership intervention showed greater self-management in dietary sodium behaviours than patients who received a minimal intervention (Dunbar et al., 2005). The three theories discussed above all focus on different aspects, and a combination of the theories might be promising. A study by Chatzisarantis, Hagger and Brickell (2008) provides support for the merit of integrating theories when explaining behaviour change. They show that the construct of perceived autonomy support in self-determination theory helps to identify the influences that others exert on intentions. They suggest that it may be worthwhile to include this idea in Ajzen's (1991) theory of planned behaviour. For this reason, we integrated the three theories described above into the development of our intervention.

\section{Outline intervention}

The intervention was a course for a minimum of five patients aged 18-64 years who were being prepared for dialysis, or were on dialysis for less than one year, and their partners. The course comprised six 2.5-hour sessions every two weeks, and one return session after three months. Course material for participants included a handbook which contained assignments and practical and theoretical information. The course focused on changing both misperceptions and negative perceptions of illness and treatment, increasing belief in self-efficacy, and stimulating social support. It was delivered by a health psychologist in cooperation with a nephrologist and an employment expert.

\section{Content sessions}

For the first three sessions we followed the method developed by Petrie et al. (1996, 2002). In the first session, information is given about the illness and treatment by a nephrologist. Next, the illness and treatment perceptions of the participants are explored and discussed in order to recognize different beliefs and coping strategies. In the second session, the participants' beliefs about the importance and attainability of activities related to work and private life are explored and discussed. Topics such as work adjustments and employment legislation are addressed by an employment expert. Questions, personal experiences and wishes are discussed, and perceived opportunities encouraged if attainable. In both the first and second sessions, special attention is given to ideas about consequences: particularly beliefs that activities including employment cannot be combined with dialysis. Negative beliefs and misperceptions are challenged by highlighting positive beliefs, giving practical examples, and addressing personal stories of ESRD patients which are described throughout the course book, thus broadening participants' views on the opportunities available. In the third session, special attention is given to beliefs about personal control and information 
provided on the relationship between events (for example starting with treatment), beliefs, feelings, and behaviour, and on the importance of turning negative thoughts into constructive ones. In preparation for this session, all the patients are asked to think of one employment and one private life goal: for example, collecting for charity or starting a walking programme. They are asked, then, to evaluate these goals based on personal importance and attainability. The patients' goals are discussed within the group and adjusted if necessary. Subsequently, patients divide their main goals into subgoals and learn how to develop an action plan in order to reach these goals and ultimately their main goals. From this third session onwards, the patients develop and carry out an action plan every two weeks, helped by their partners. In these three sessions, observational learning techniques are used, such as didactic teaching, written material, examples of personal stories from peers, and group discussion. Changing inadequate perceptions is a first step towards behavioural change, but support for selfefficacy and autonomy is necessary to actually perform the intended behaviour. In sessions four to six the focus is on these aspects. Beliefs in self-efficacy in relation to activities, including employment, are explored and enhanced using techniques such as self-monitoring, guided mastery of skills through two-weekly action plans and feedback on progress, modelling of selfmanagement behaviours and problem-solving strategies. In session four, special attention is given to fatigue. In preparation for the session the patients keep a daily fatigue diary to gain insight into existing complaints about fatigue and its patterns. Experiences are discussed and information is given on how to manage time and energy in an adequate way by structuring and setting priorities. In session five, attention is paid particularly to the role of the social network. The patients who participate without a partner are invited to bring along a family member or friend. Supportive and unsupportive behaviours are discussed, together with ways to ask for support. Partners, family members, or friends learn to give support and to prevent overprotection, and the patients learn how to ask for support in an adequate way. In session six, the participants develop an action plan for an employment goal for the next three months. Advice is given on which steps to take and how to contact relevant parties, such as employers and company doctors. In preparation for this session, all the patients are asked to think of an employment goal, and to check whether this is attainable and important to them. During the session the patients' goals are discussed and adjusted if necessary. Subsequently, they develop a plan together with their partners under the guidance of the employment expert and the health psychologist. They then discuss their plans within the group. During the return session, the outcome of their action plans related to employment is evaluated within the group under the guidance of the health psychologist and employment expert. The participants discuss what the course has given to them, paying attention to how one can maintain or widen the goals that have been achieved.

\section{Pilot intervention}

In the months from April to August 2008 the intervention was piloted, testing whether it was feasible and initial experiences. During this period patients and their partners received a course in three dialysis centres situated in the centre of the Netherlands. In February 2008, patients were recruited by the social workers based in the participating dialysis centres on the basis of a range of criteria. These comprised the following, where the patient:

is experiencing decreased renal function and renal replacement therapy is inevitable (ESRD); is being prepared for dialysis, or receiving dialysis for a maximum period of 12 months; is aged 18-64 years; is able to speak Dutch sufficiently; is able to perform work; has sufficient intellectual capacities to participate in the course and study; and is not undergoing psychological, psychotherapeutic or psychiatric treatment.

All the meetings were held in one of the three centres. Feasibility and experiences were investigated through evaluation forms and interviews.

\section{Implementing the intervention}

The social workers were positive about the organization of the course. Two social workers stated that recruiting the participants resulted in a minimal burden. For the other two it was a substantial burden, but manageable. Neither they, nor the other health care providers, nephrologists and dialysis nurses, received an increase in requests for information and support from participating patients. The social workers stated that the number and nature of their contacts with the participants remained the same throughout the course. 


\section{Recruitment and retention}

Twenty-eight eligible patients were selected and received information on the course and the study; ten of them signed up. Reasons for not responding were mostly due to not being able to fit the course into one's daily schedule. Three patients dropped out without attending any meetings because of health reasons, resulting in seven patients participating. All participating patients lived with a partner, and five of them took part with their partner. There were four men and three women with a mean age of 48.7 years. Six patients performed paid work $(M=21.8$ hrs per week; $S D=11.3$, range 4.5-40), and one patient was unemployed. No patients withdrew during the course. Among the participating partners were two men and three women.

\section{Acceptability Course participants' views}

The majority of the participants were satisfied with the length, number, and frequency of the meetings, although experiences varied with regard to the times at which the course was held. All participants liked to work in a group. The mixture of experiences and information of both pre-dialysis and dialysis patients was highly valued. The participants rated all the meetings (considerably) useful according to a threepoint scale: 'useful', 'considerably useful', and 'not useful'. The meetings which were indicated most often as useful were those in which the action plan was introduced, the topic of fatigue addressed and focus placed on developing an action plan for a long-term employment goal. According to a majority of the participants the various aspects of living with ESRD received sufficient attention. However, the need for information differed between the participants. Some reported that they were interested in more information on certain addressed topics, such as dialysis and employment legislation, while others were not. Furthermore, two participating partners wanted more attention given to the role of partners and the exchange of partners' experiences. Action plans were important elements within the course. The great majority considered the action plans as useful (7/9) and the number of plans as good (9/10). Five out of ten participants appreciated the degree of difficulty posed by the action plans. However, an equal part thought that it was difficult. Notwithstanding this, most considered the action plans to be practical (6/10). Furthermore, the participants stated that all the assignments within the course were useful. The fatigue diary and the action plans were regarded as most helpful. One partner responded that thinking about ways to help their partner to cope with the illness was very useful. The participants largely indicated that the course leaders addressed individual needs, situations, and questions adequately and were much involved with the group (Table 1).

\section{Course leaders' views}

According to the course leaders, the participants preferred to work in groups, as this provided much discussion, cooperation, motivation, and mutual interest. They would like to see larger groups that would enable greater opportunities for cooperation and discussion. In order to monitor the group process and course content, it is proposed that two main course leaders deliver the course. The course leaders had good experiences with course feasibility and delivery, and indicated that course content corresponded with the participants' personal needs and situations. In order to optimize this link, it was felt that general information should be reduced while participants' personal contribution promoted. Furthermore, it was advised that there should be more opportunities for partners to exchange experiences. The participants sometimes had difficulty doing the exercises: therefore, it is recommended that work on the various exercises should be conducted mainly in subgroups. In addition, more time should be spent on the discussion before and after the exercises, in particular the action plans. The course leaders stated that the group composition was good, although they stress that it is important to maximize efforts to include patients shortly after diagnosis. In this phase of the illness, patients often have no insight into the consequences of the illness and treatment for their daily life. As a result they are not able to anticipate necessary adjustments in order to prevent problems with employment. Therefore, this group of patients are likely to benefit the most from the assistance offered in the course.

\section{[TABLE 1]}


Jansen, D.L., Heijmans, M., Rijken, M., Kaptein, A.A. The development of and first experiences with a behavioural self-regulation intervention for end-stage renal disease patients and their partners. Journal of Health Psychology: 2011, 16(2), 274-283

The patients were asked if they were able to work on their goals during the course. One responded that he had been able to do a lot of work on his goals; three indicated that they had worked on their goals quite a lot, and another three stated that they were able to work on their goals to some extent. Several patients observed changes in their personal situations. One patient stated: 'I have found a job, do more at home and I have become more active in general.' Several patients indicated that by using the action plans and fatigue diaries they were able to divide their time and energy better during the day. Furthermore, the answers showed that some patients had learned to integrate their social environment into their illness and treatment. For example, one said: 'I am more aware of the fact that you have to explain the illness and its limitations to everyone, and have to keep your employer informed about the situation.' Most patients (4/7) indicated that they are planning to put the things they have learned into practice in the future.

Participants valued the course with an average grade of 7.6 on a scale from 1 to 10 . All participants recommended the course to other patients and their partners. Examples of accompanying statements are as follows:

The course gives insight into how 'healthy' you still are, and what, and howmuch, you still can do.

A wonderful way to learn what you should do to stay in work. By means of a good personal action plan you build energy into your daily life. You know how you would like to reach for your goals, and that gives you peace of mind.

\section{DISCUSSION}

The first aim of this study was to develop a psychological intervention to assist ESRD patients and their partners in integrating renal disease and treatment into their daily activities, primarily work, and thereby increasing their autonomy. The focus of the intervention can be divided into three aspects. The first was to stimulate positive but realistic beliefs about the disease, treatment, and the opportunities to stay active in both patients and partners - and in so doing, to change maladaptive beliefs. The second was to increase patients' self-efficacy. The final aspect was to stimulate behaviour that supports autonomy in both patients and partners. The second aim of this study was to test how feasible the intervention was and to evaluate the first experiences of the participants, course leaders and health care providers involved. We were successful in developing an intervention which addressed the cognitive, emotional, behavioural, and contextual aspects important for patients' self-regulatory processes. Furthermore, implementation of the intervention in a clinical setting was successful. The participating dialysis centres were strongly supportive of the intervention, since all the three centres endorsed the necessity of this type of assistance. The cooperation with the three dialysis centres worked well, in that together the centres approached enough potential participants; however, the rate of participation was lower than expected. The reasons for not responding indicate that it is important for the course to be fitted into participants' daily lives. In future, consideration should be given to where and when the meetings are held and how participants can get there. When we compare the patients approached with those who actually participated, we found that no patients younger than 30 took part, although some were approached. More efforts are needed to reach this group. It is advisable to emphasize that besides employment, attention is given to education and training. None of the seven participating patients withdrew from the course, which indicates that all patients regarded the course as useful. On the whole, the participants and course leaders were positive about the course format. Participants were less satisfied about the times at which the course was held. Preference for course times seems to be very personal, since patients' dialysis and work schedules differ. These findings highlight the importance of flexibility in scheduling future courses. One could think of giving the intervention to patients at the dialysis centre while they are on dialysis, or adapting dialysis or work schedules in cooperation with health care providers or employers. Important elements within the course included group discussion, giving examples of practice, and didactic teaching. These elements were strategies to broaden participants' views on the available opportunities and, in so doing, to promote positive beliefs. This was endorsed by one of the patients, who stated that the course gave insight into how 'healthy' you still are, and what and how much you still can do. We chose a group format instead of an individual format, since peer modelling and peer support are useful strategies to influence beliefs about illness, treatment and self-efficacy. All participants held positive attitudes towards the group element, and indicated that they valued the opportunity to 
exchange knowledge and experiences and had learned from it. However, a group could inhibit the expression of difficulties and emotions. Consequently, it is important to create a trusted atmosphere by means of an extensive introduction around the group and occasionally putting participants together to work in smaller groups. The course leaders indicated that there was a lot of open discussion, cooperation and mutual interest, and thought that it was important to increase these opportunities in order to improve the group process and, in turn, the learning process. This should be done by increasing the number of patients to at least eight. However, when working with larger groups it is essential to have two main course leaders, so that the process with respect to both content and the group will be warranted. The course leaders stress that more effort is needed to include patients shortly after diagnosis, in order to assist them during the early phase of the illness and to work preventatively. Moreover, research suggests that interventions to change cognition should focus on patients at an early stage of the illness (Petrie et al., 2002). The fact that various disciplines, and consequently knowledge, come together in an early phase of the illness, can be seen as a great advantage of the course. The topics addressed within the course appeared to be relevant to all the participants. However, one area for attention is how the information given is tailored to individual preferences. The differences in these preferences may be partly caused by the differences in participants' stages of illness and/or treatment. Therefore, the amount of general information should be reduced and more time spent on exploring and discussing individual needs for information: this can be done throughout the course or by organizing separate question times. Furthermore, it was suggested that more opportunities should be created for partners to exchange experiences with respect to how they deal with their partners' illness. Partners could work in separate groups occasionally, so that they can talk about their experiences more freely. Clark and Dunbar (2003) stress the importance of taking into account family members' experiences and their own need for support. The participants' attitudes towards the exercises were good, particularly the fatigue diary and action plans. These exercises aimed to provide a framework for ways to structure activities and make them more accessible, thus lowering the threshold for carrying them out and consequently promoting patients' belief in self-efficacy. Patients indicated that these exercises meant they were more able to divide their time and energy during the day, and one patient stated that creating plans to reach goals gave him peace of mind. However, some participants encountered difficulties with the exercises: it is recommended that this problem should be tackled by working in small groups, paying more attention to discussion and giving more examples, so that participants are able to relate to them better. In addition, patients' self-observed results from the course were encouraging. The health care providers reported no unfavourable consequences from their cooperation with the course. Moreover, in the long run, health care providers, especially social workers, might experience favourable consequences, since it can be expected that an intervention of this kind prevents problems, or anticipates problems, which social workers normally encounter in their regular care.

\section{CONCLUSION}

The current study meets the emerging need for research regarding development and evaluation of selfregulatory based interventions aimed at improving patient outcomes (Petrie et al., 2007) and ESRD patients outcomes in particular (Griva et al., 2009; Timmers et al., 2008). Further research is needed to evaluate the actual effectiveness of the course, both in the short-term and the long run. It needs to ask whether the course leads to fewer patients dropping out of the employment market and results in increased feelings of autonomy. Findings from this pilot study are encouraging and suggest that an approach driven by theory in which cognitive, emotional, behavioural, and contextual aspects are integrated is promising. The maintenance of paid employment and reintegration are complex processes. A positive attitude, social support, as well as a belief in self-efficacy, are needed. Many reintegration programmes use action plans by which goals are reached in small steps, but for these plans to be effective it is of great importance that the patients themselves support these goals. They should be autonomous rather than controlled. The study revealed factors that are important for the development and implementation of psychological interventions in general, and identified challenges for future interventions.

\section{REFERENCES}

Ajzen, I. (1991). The theory of planned behavior. Organizational Behavior and Human Decision Processes, 50, 179-211. 
Jansen, D.L., Heijmans, M., Rijken, M., Kaptein, A.A. The development of and first experiences with a behavioural self-regulation intervention for end-stage renal disease patients and their partners. Journal of Health Psychology: 2011, 16(2), 274-283

Baard, P. P., Deci, E. L., \& Ryan, R. M. (2004). Intrinsic need satisfaction: A motivational basis of performance and well-being in two work settings. Journal of Applied Social Psychology, 34, $2045-2068$. Bandura, A. (1977). Social learning theory. Englewood Cliffs, NJ: Prentice-Hall.

Bandura, A. (1997). Self-efficacy: The exercise of control. New York: W.H. Freeman.

Braun Curtin, R., Oberly, E. T., Sacksteder, P., \& Friedman, A. (1996). Differences between employed and non-employed dialysis patients. American Journal of Kidney Diseases, 27, 533-540.

Chatzisarantis, N. L. D., Hagger, M. S., \& Brickell, T. (2008). Using the construct of perceived autonomy support to understand social influence within the theory of planned behavior. Psychology of Sport and Exercise, 9, 27-44.

Clark, P.C., \& Dunbar, S. B. (2003). Family Partnership Intervention: A guide for a family approach to care of patients with heart failure. AACN Clinical Issues, 14(4), 467-476.

Deci, E., \& Ryan, R. (1985). Intrinsic motivation and self determination in human behaviour. New York: Plenum.

Deci, E. L., La Guardia, J. G., Moller, A., Scheiner, M. J., \& Ryan, R. M. (2006). On the benefits of giving as well as receiving autonomy support: Mutuality in close friendships. Personality and Social Psychology Bulletin, 32, 313-327.

Dunbar, S. B., Clark, P. C., Deaton, C., Smith, A. L., De, A. K., \& O’Brien, M.C. (2005). Family education and support interventions in heart failure: A pilot study. Nursing Research, 54(3), 158-166.

Grassmann, A., Gioberge, S., Moeller, S., \& Brown, G. (2006). End-stage renal disease: Global demographics in 2005 and observed trends. Artificial Organs, 30, 895-897.

Griva, K., Jayasena, D., Davenport, A., Harrison, M., \& Newman, S. P. (2009). Illness and treatment cognitions and health related quality of life in end stage renal disease. British Journal of Health Psychology, 14, 17-34.

Hagger, M. S., \& Orbell, S. (2003). A meta-analytic review of the common-sense model of illness representations. Psychology and Health, 18, 141-184.

Heijmans, M. J. W. M., \& Rijken, P. M. (2004). Sociaalmaatschappelijke participatie van mensen met een chronische nierinsufficiëntie. Een literatuurstudie naar de ervaren knelpunten en mogelijkheden. [Social participation of people with chronic renal insufficiency. A literature study on experienced obstacles and opportunities.] Utrecht: NIVEL.

Horne, R. (1997). Representations of medication and treatment: Advances in theory and measurement. In K. Petrie \& J. Weinman (Eds.), Perceptions of health and illness: current research and applications (pp. 155-188). London: Harwood Academic.

Horne, R. (2003). Treatment perceptions and self regulation. In L. D. Cameron \& H. Leventhal (Eds.), The self regulation of health and illness behaviour (pp. 138-153). London: Routledge. Jansen, D. L., Heijmans, M. J. W. M., Boeschoten, E. W., \& Rijken, P. M. (2009). Bevordering van arbeidsparticipatie en autonomie van nierpatiënten. [Promotion of labour participation and autonomy of renal patients.] Utrecht, The Netherlands: NIVEL.

Jansen, D. L., Grootendorst, D. C., Rijken, P. M., Heijmans, M. J. W. M., Kaptein, A. A., Boeschoten, E. W., et al. (submitted) Pre-dialysis patients' labour participation, perceived autonomy and self-esteem: associations with illness and treatment perceptions. Jansen, D. L., Rijken, P. M., Heijmans, M. J. W. M., \& Boeschoten, E. W. (in press). Perceived autonomy and self-esteem in Dutch dialysis patients: The importance of illness and treatment perceptions. Psychology and Health.

Karamanidou, C., Weinman, J., \& Horne, R. (2008). Improving haemodialysis patients' understanding of phosphate-binding medication: A pilot study of a psycho- educational intervention designed to change patients' perceptions of the problem and treatment. British Journal of Health Psychology, 13, $205-214$. Kasser, V. M., \& Ryan, R. M. (1999). The relation of psychological needs for autonomy and relatedness to health, vitality, well-being and mortality in a nursing home. Journal of Applied Social Psychology, 29, 935954.

Khan, I. H., Garratt, A. M., Kumar, A., Cody, D. J., Catto, G. R. D., Edward, N., et al. (1995). Patients' perception of health on renal replacement therapy: Evaluation using a new instrument. Nephrology Dialysis Transplantation, 10, 684-689.

Leventhal, H., Meyer, D., \& Nerenz, D. (1980). The common sense representation of illness danger. In S. Rachman (Ed.), Medical psychology (pp. 7-30). New York: Pergamon.

Leventhal, H., Nerenz, D. R., \& Steele, D.J. (1984). Illness representations and coping with health threats. In A. Baum, S. E. Taylor, J. E. Singer (Eds.), Handbook of psychology and health (pp. 219-252). Hillsdale, NJ: Lawrence Erlbaum Associates.

Lorig, K. R., Sobel, D. S., Stewart,A. L., Brown., B.W. Jr., Ritter, P. L., González, V.M., et al. (1999). Evidence suggesting that a chronic disease self-management program can improve health status while reducing utilization and costs: A randomized trial. Medical Care, 37, 5-14. 
Jansen, D.L., Heijmans, M., Rijken, M., Kaptein, A.A. The development of and first experiences with a behavioural self-regulation intervention for end-stage renal disease patients and their partners. Journal of Health Psychology: 2011, 16(2), 274-283

Lorig, K. R., Ritter, P., Stewart, A. L., Sobel, D. S., Brown, B. W., Bandura, A., et al. (2001). Chronic disease selfmanagement program. 2-year health status and health care utilization outcomes. Medical Care, 39, 1217-1223.

Martire, L. M. (2005). The 'relative' efficacy of involving family in psychosocial interventions for chronic illness: Are there added benefits to patients and family members? Families, Systems \& Health, 23, 312 328.

Merkus,M. P., Jager, K. J., Dekker, F.W., Boeschoten, E.W., Stevens, P., \& Krediet, R. T. (1997). Quality of life in patients on chronic dialysis: Self-assessment 3 months after the start of treatment. The NECOSAD Study Group. American Journal of Kidney Diseases, 29, 584-592.

Merkus, M. P., Jager, K. J., Dekker, F. W., De Haan, R. J., Boeschoten, E. W., \& Krediet, R. T. (1999). Physical symptoms and quality of life in patients on chronic dialysis: Results of The Netherlands Cooperative Study on Adequacy of Dialysis (NECOSAD). Nephrology Dialysis Transplantation, 14, 11631170.

Mittal, S. K., Ahern, L., Flaster, E., Maesaka, J. K., \& Fishbane, S. (2001). Self-assessed physical and mental function of haemodialysis patients. Nephrology Dialysis Transplantation, 16, 1387-1394.

Moss-Morris, R., Humphrey, K., Johnson, M. H., \& Petrie, K. J. (2007). Patients' perceptions of their pain condition across a multidisciplinary pain management program: Do they change and if so, does it matter? Clinical Journal of Pain, 23, 558-564.

Murtagh, F. E. M., Addington-Hall, J., \& Higginson, I. J. (2007). The prevalence of symptoms in end-stage renal disease: A systematic review. Advances in Chronic Kidney Disease, 14, 82-99.

Petrie, K. J., Weinman, J., Sharpe, N., \& Buckley, J. (1996). Role of patients' view of their illness in predicting return to work and functioning after myocardial infarction: longitudinal study. British Medical Journal, 312, 1191-1194.

Petrie, K. J., \& Weinman, J. A. (1997). Perceptions of health and illness. London: Harwood Academic Publishers.

Petrie, K. J., Cameron, L. D., Ellis, C. J., Buick, D., \& Weinman, J. (2002). Changing illness perceptions after myocardial infarction:An early intervention randomized controlled trial. Psychosomatic Medicine, 64, 580-586.

Petrie, K. J., Jago, L. A., \& Devcich, D. A. (2007). The role of illness perceptions in patients with medical conditions. Current Opinion in Psychiatry, 20, 163-167.

Theorell, T., Konarski-Svensson, J. K., Ahlmen, J., \& Perski, A. (1991). The role of paid work in Swedish chronic dialysis patients - a nation-wide survey: Paidwork and dialysis. Journal of Internal Medicine, 230, 501-509.

Timmers, L., Thong, M., Dekker, F. W., Boeschoten, E. W., Heijmans, M., Rijken, M., et al. (2008). Illness perceptions in dialysis patients and their association with quality of life. Psychology and Health, 23,679 690.

Van Manen, J. G., Korevaar, J. C., Dekker, F. W., Reuselaars, M. C., Boeschoten, E. W., \& Krediet, R. T. (2001). Changes in employment status in end-stage renal disease patients during the first year of dialysis. Peritoneal Dialysis International, 21, 595-601. Waddell, G., \& Burton, A. K. (2006). Is work good for your health and well being? London: The Stationery Office.

Williams, G. C., Rodin, G. C., Ryan, R.M., Grolnick,W. S., \& Deci, E. L. (1998). Autonomous regulation and longterm medication adherence in adult outpatients. Health Psychology, 17, 269-276.

Williams, G. C., Lynch, M. F., McGregor, H., Ryan, R. M., Sharp, D., \& Deci, E. L. (2006). Validation of the Important Other Climate Questionnaire: Assessing autonomy support for health related change. Families, Systems and Health, 24, 179-194.

\section{[TABLES]}

Table 1. Participants' experiences with course leaders $(N=11)$

\begin{tabular}{lllll}
\hline & Not at all & Somewhat & Quite a lot & Very much \\
\hline Were your personal situation and needs considered? & 0 & 1 & 7 & 3 \\
Was there attention for your questions and needs? & 0 & 1 & 4 & 6 \\
Was the provided feedback clear? & 0 & 1 & 6 & 4 \\
Was the information provided clear? & 0 & 0 & 6 & 3 \\
Was there involvement with respect to the group? & 0 & & 5 \\
\hline
\end{tabular}

